\title{
"Imagens" políticas do Brasil: uma sequência didática com meme da internet nas aulas de Língua Portuguesa
}

\author{
Maria Alice de Souza ${ }^{\mathrm{i}}$ \\ Marcelo Diniz Monteiro de Barros ${ }^{\text {ii }}$ \\ Lana Mara Castro Siman ${ }^{\mathrm{iii}}$
}

\footnotetext{
${ }^{i}$ Mestre em Educação e Formação Humana na Universidade do Estado de Minas Gerais (2019). Graduada em Letras pela Universidade Federal de Minas Gerais (1996), possui especialização em Educação, Mídias e Tecnologias pela Universidade do Estado de Minas Gerais (2007). Atualmente leciona Língua Portuguesa na Escola Estadual Maria de Lourdes de Oliveira. http://orcid.org/0000-0001-5498-9289 | mariaalicepos@gmail.com
}

ii Possui Graduação em Ciências Biológicas pela Pontifícia Universidade Católica de Minas Gerais (1997), Especialização em Ensino de Ciências pela Universidade Federal de Minas Gerais (1999), Mestrado em Zoologia de Vertebrados pela Pontifícia Universidade Católica de Minas Gerais (2006), Doutorado em Ensino em Biociências e Saúde pelo Instituto Oswaldo Cruz - Fundação Oswaldo Cruz (2014) e Pós-Doutorados em Ensino em Biociências e Saúde pelo Instituto Oswaldo Cruz - Fundação Oswaldo Cruz (2016 e 2018). Trabalha na Faculdade de Educação da Universidade do Estado de Minas Gerais (UEMG), como Professor Nível IV, Grau A, lecionando a disciplina Ciências da Natureza na Educação Infantil e em Anos Iniciais do Ensino Fundamental e, também, como Professor do Programa de Pós-Graduação em Educação e Formação Humana. Aprovado em primeiro lugar em concurso público para a Universidade do Estado de Minas Gerais - Edital SEPLAG / UEMG no 08/2014, vaga ${ }^{\circ} 165$ (UM1074): Ciências da Natureza na Educação Infantil e em Anos Iniciais do Ensino Fundamental (40 horas, sem dedicação exclusiva). Belo Horizonte - Unidade: Faculdade de Educação.

http://orcid.org/0000-0003-4420-5406 | marcelodiniz@ pucminas.br

iii Doutora em Didática da História pela Université Laval/Canadá (1997). Professora aposenta da Faculdade de Educação da UFMG; Professora efetiva e em exercício da Faculdade de Educação da Universidade Estado de Minas Gerais UEMG , sendo corpo permanente Programa de Pós-Graduação em Educação(stricto-sensu) dessa mesma instituição; líder do Grupo de Pesquisa Polis \& Mnémosine: Educação, cultura e memória da UEMG, pesquisadora do LABEPEH UFMG; pesquisadora do grupo Cronos e da Participou da rede de correspondentes internacionais da Revista Le cartable de Clio (Suíça), do conselho científico da Revista IBER ( Barcelona), foi membro do comité editorial e editora chefe da Revista Educação em Foco de Minas Membro da Câmara de Assessoramento Ciências Humanas e Educação , da FAPEMIG. No mestrado em Educação da UEMG participa da linha de pesquisa Culturas, Memórias e Linguagens em Processos Educativos. Tem longa experiência em formação de professores, com ênfase em Ensino e aprendizagem de História, saberes e práticas docente, atuando e investigando nos temas: Educação, História e Memória; Educação Patrimonial; Educação Museal, História local e políticas curriculares; educação das sensibilidades. Desenvolve projeto de pesquisa em parceria nacional com o Museu do Ouro /IBRAM e internacional com Université Laval Québec/Canadá junto à CLÉ Sciences et Développement durable. http://orcid.org/0000-0002-8061-9924 | lanacastrosiman@gmail.com 


\section{RESUMO}

$\mathrm{Na}$ era digital, as práticas de comunicação compreendem gêneros que combinam elementos verbais, visuais e audiovisuais. Assim, com o objetivo de ampliar a significação da leitura, este relato de experiência apresenta uma reflexão a partir de uma sequência didática desenvolvida com alunos do ensino médio de uma escola pública da rede estadual de Belo Horizonte, utilizando o gênero meme da internet nas aulas de Língua Portuguesa. Quanto à metodologia, este texto apresenta uma revisão literária, que aponta o meme enquanto objeto que oportuniza compreender concomitantemente aspectos do convívio social e valores que circulam no ambiente virtual. Nesse sentido, para se ler efetivamente um meme, os sujeitos devem apresentar habilidades voltadas tanto para o domínio da linguagem verbal como da imagética. Como resultado, o trabalho mostrou que os memes extraídos de sites, blogs e redes sociais podem contribuir para que os alunos compreendam as práticas de uso e reflexão da língua.

Palavras-chave: Meme da internet; Língua Portuguesa; Sequência didática; Leitura.

\section{RESUMEN}

En la era digital, las prácticas comunicativas comprenden géneros que combinan elementos verbales, visuales y audiovisuales. Así, con el objetivo de ampliar el significado de la lectura, este relato de experiencia presenta una reflexión a partir de una secuencia didáctica desarrollada con estudiantes de la secundaria de una escuela pública de la red estatal de Belo Horizonte, utilizando el género meme de internet en clases de Lengua portuguesa. En cuanto a la metodología, este texto presenta una revisión literaria, que apunta al meme como un objeto que permite comprender de manera concomitante aspectos de la vida social y valores que circulan en el entorno virtual. En este sentido, para leer un meme de manera eficaz, los sujetos deben tener habilidades enfocadas tanto en el dominio del lenguaje verbal como en las imágenes. Como resultado, el trabajo mostró que los memes extraídos de sitios web, blogs y redes sociales pueden contribuir a que los estudiantes comprendan el uso del lenguaje y las prácticas de reflexión.

Palabras clave: Meme de Internet; Lengua portuguesa; Secuencia didáctica; Lectura. 
"Imagens" políticas do Brasil: uma sequência didática com meme da internet nas aulas de Língua Portuguesa

\section{INTRODUÇÃO}

Em seu cotidiano, os indivíduos lidam com diversos gêneros discursivos e suas intenções comunicativas, não prevalecendo hoje a ideia de que um texto é composto unicamente de signos verbais. Nesse sentido, as imagens não são mais vistas como simples ilustrações dos textos verbais, dizendo do contexto em que estão inseridas ou tendo funções distintas das palavras (FARACO, MOURA; MARUXO, 2016).

Sob essa perspectiva, na web, por exemplo, os eventos discursivos ficariam incompreensíveis se as imagens e seus elementos gráficos - cores das letras, ícones, desenhos - fossem eliminados. Além disso, com o advento da internet, certos gêneros apenas se materializam por ser o cruzamento das linguagens verbal e não verbal. Em outras palavras, na era digital, os textos se compõem num ritmo muito veloz, em que imagens se combinam com palavras na construção dos sentidos (FARACO, MOURA; MARUXO, 2016).

Esse panorama aponta, ainda, para o quanto os sujeitos recorrem frequentemente às imagens no dia a dia para exteriorizar suas interpretações ou estabelecer modos de interação social. De acordo com Kress e van Leeuwen (2006), na comunicação visual, as imagens, além de transmitirem uma mensagem, atuam como modo de representação, negociação de identidade e relações sociais, produzindo significados ideacionais, interpessoais e textuais, ou seja, os diferentes usos das imagens na vida social ressignificam o mundo de maneira menos utilitária. Belmiro (2000, p. 14) entende que a imagem permite a contiguidade física do signo com seu referente, constituindo-se num “conjunto de significado do todo social".

Diferenciando-se da cultura do impresso, o ambiente digital produziu novas organizações textuais e configurações visuais que modificaram a relação entre texto e leitor (PEREIRA, 2012). Sob esse ponto de vista, Ribeiro (2013) afirma que, na contemporaneidade, muitas composições nascem verbo-visuais, ou seja, são constituídas por palavras e imagens desde sua origem. Nessa perspectiva, as produções são concebidas a partir de um projeto textual e gráfico, que demanda de seus leitores uma ação, que é uma performance sustentada pelas noções de como os textos são delineados.

Assim, considerando que os sujeitos estão cercados de textos icônico-verbais e que o critério de distribuição entre imagens e palavras no espaço gráfico leva a 
determinadas compreensões, o desafio do componente Língua Portuguesa é preparar os alunos para uma leitura eficiente desses textos, já que o equilíbrio entre o não verbal e o verbal não é recorrente (FARACO, MOURA; MARUXO, 2016).

Diante do exposto, este relato tem como finalidade divulgar os resultados das ações realizadas em uma sequência didática na disciplina Língua Portuguesa, em que os alunos realizaram uma leitura efetiva de textos icônico-verbais, construindo uma representação sociopolítica do Brasil, entre os anos de 2014 e 2019, por intermédio do meme da internet.

Quanto ao procedimento metodológico, esta investigação se enquadra como relato de experiência profissional por apresentar e refletir sobre as etapas de uma sequência didática desenvolvida com alunos do primeiro ano do ensino médio de uma escola pública da rede estadual do município de Belo Horizonte. Além disso, mediante revisão de literatura com um recorte qualitativo, este texto apresenta uma visão concisa do gênero meme da internet, considerando sua estrutura, tipos de enunciados, inserção sociocultural e práticas sociais de leitura a ele atreladas.

A sequência didática foi escolhida por permitir que a aprendizagem fosse alcançada por intermédio de um conjunto de atividades planejadas (DOLZ; NOVERRAZ; SCHNEUWLY, 2004), tendo como ponto de partida o meme da internet. Apesar de lembrar um plano de aula, o procedimento é mais amplo por utilizar diferentes estratégias de ensino-aprendizagem no decorrer de vários dias (KOBASHIGAWA et al., 2008). Ademais, pela sequência didática, o trabalho com os alunos pode ser articulado envolvendo outros eixos do ensino de língua, como a oralidade, a leitura, a produção de texto e a análise linguística (DOLZ; NOVERRAZ; SCHNEUWLY, 2004).

No entanto, ressalta-se que, no presente caso, a intenção da sequência não foi auxiliar o aprendiz no domínio de um gênero discursivo, uma vez que o meme da internet já se encontra profundamente relacionado à cultura jovem, mas ela foi organizada visando promover uma discussão voltada para o funcionamento e os usos do gênero, que reúne padrões culturais e interacionais da sociedade no qual está inserido. Longe de ser pretexto para o ensino de atividades voltadas para a gramática normativa, o meme foi o meio para se atingir a língua. Nesses princípios, conforme 
"Imagens" políticas do Brasil: uma sequência didática com meme da internet nas aulas de Língua Portuguesa

Antunes (2002), o ensino da língua se torna eficaz por escolher o próprio texto como objeto de estudo.

Quanto à estruturação, este relato é organizado em quatro partes: nesta introdução, em que há a delimitação do tema, as motivações para a sequência didática e a metodologia empregada; na segunda parte, em que são revistadas algumas concepções sobre práticas sociais de leitura e particularidades do meme da internet; na terceira parte, em que uma sequência didática desenvolvida nas aulas de Língua Portuguesa mostra aspectos relacionados à leitura crítica do meme da internet e, por fim, nas considerações finais, uma síntese do trabalho é apresentada.

\section{PRÁTICAS SOCIAIS DO MEME DA INTERNET}

Enquanto tecnologia, a internet determina um aprendizado dentro de uma comunidade global, exigindo novas capacidades para que os sujeitos possam acessar totalmente seu potencial (MARCUSCHI, 2005). Nesse sentido, provenientes das inovações tecnológicas, os gêneros digitais surgiram das necessidades e das atividades socioculturais no novo panorama (PEREIRA, 2012).

Ao contrário dos gêneros tradicionais, os gêneros digitais integram uma série de símbolos e formatos de mídia múltipla, incluindo ícones, símbolos animados, áudio, vídeo, tabelas interativas e ambientes de realidade virtual. Sob essa perspectiva, ser letrado significa adotar mudanças nas maneiras de ler e escrever códigos verbais e não verbais na cultura da tela. A propósito, Soares (2002) afirma que as tecnologias digitais reorganizaram os espaços da escrita e da leitura, criando relações entre escritor e texto, entre escritor e leitor, entre leitor e texto. Para a autora, a tela como espaço de leitura e de escrita trouxe significativas mudanças na relação escritor-texto-leitor, já que os processos cognitivos dessa prática social de leitura oportunizaram outros modos de acesso à informação e ao conhecimento, aproximando os sujeitos de seus esquemas mentais.

Desse modo, entendendo que as práticas socias comportam em si também a linguagem visual, Belmiro (2000, p. 16) esclarece que, por sua natureza midiática, uma imagem é representação, ou seja, o que se vê é "tradução de um modo de organização do olhar", que cria modos de apropriação do visível, influenciado pelas inovações 
técnicas, numa lógica presa "a um conjunto de fatores históricos, sociais, científicos". A autora ainda alerta que, embora as imagens ordenem a maneira de os indivíduos perceberem o mundo que os cerca, muitas vezes eles não possuem um aprendizado sistematizado de seus modos de leitura. Em outras palavras, muitos leitores desconhecem como se organizam os componentes de uma imagem, como enquadramento, corte, distância, ângulo, seleção ou não de cor, textura.

Mediante o exposto e considerando que, por intermédio dos gêneros discursivos, o ensino da língua se mostra mais produtivo, o meme da internet foi escolhido como objeto de estudo por proporcionar uma abordagem que supera o fato gramatical. Por certo, quem lê ou produz um meme da internet não possui apenas habilidades voltadas para a linguagem escrita, domina também a linguagem oral e a imagética (ESCALANTE, 2016). E, como uma representação do real, as imagens presentes nas peças evocam uma narrativa, já que compõem analogias que criam enredos (BELMIRO, 2012).

Assim, para fundamentar a escolha desse gênero, é importante ressaltar que o meme da internet possui, inicialmente, uma natureza hipertextual, já que a construção de seu sentido exige a articulação de conhecimentos prévios vindos de diferentes fontes. Coscarelli (2006), ao abordar as características dos gêneros textuais, mostra que a estrutura de um texto desempenha uma função relevante na leitura e na apreensão de seu significado. Assim sendo, todo texto apresenta conexões, fazendo referência a outro, ou seja, apesar da disposição sequencial das palavras numa produção, sua leitura envolve várias habilidades de percepção e interpretação.

Aliás, o meme da internet também é caracterizado pela intertextualidade. Shifman (2014) entende que esse recurso é identificado quando uma peça é: a) um elemento com conteúdo, forma, postura semelhantes; b) um intricado criado a partir do conhecimento de outras peças; e c) um objeto imitado, transformado e distribuído pela internet.

Nessa perspectiva, as personagens já conhecidas por aqueles que compartilham memes da internet representam circunstâncias particulares; estando, muitas vezes, vinculados a comunidades on-line específicas. Sob esse ponto de vista, Barreto (2015) acrescenta que uma unidade de imitação não desconsidera a competência cognitiva dos 
"Imagens" políticas do Brasil: uma sequência didática com meme da internet nas aulas de Língua Portuguesa

sujeitos, sendo sua evolução garantida pela seleção que os indivíduos fazem, ou seja, é a preferência por determinada peça que garante sua vida útil.

O meme da internet, nessa lógica, pode oferecer elementos para se compreender aspectos do convívio social (BARRETO, 2015); já que, em ambiente virtual, sua postagem associada aos comentários são maneiras de comunicação que permitem a formação e a complexidade de diferentes comunidades on-line (RECUERO, 2007). Por conseguinte, o estudo do meme pode auxiliar na compreensão das identidades, relações e valores que circulam nesse espaço.

Como todo texto está relacionado inerentemente a outros textos, enunciados e discursos, nenhum meme pode ser analisado sem ser correlacionado aos eventos que circulam nas redes sociais. Nas palavras de Bakhtin (1992), a língua não pode estar desvinculada da vida, sendo a natureza do enunciado e as peculiaridades do gênero aspectos que apontam para a diversidade do discurso.

Como o uso da variedade escrita da língua se modificou ao longo do tempo, deixando de ser considerada um conjunto de habilidades individuais para abarcar os expedientes socioculturais contextualizados historicamente (EUZÉBIO; CERUTTIRIZZATTI, 2013), surge o desafio de apreender como práticas sociais de leitura são introduzidas, percebendo também as circunstâncias em que elas se estabelecem.

No decorrer desta seção, o meme da internet foi compreendido em relação aos acontecimentos culturais e sociais que o cercam. Também se mostrou concepções sobre as práticas sociais de leitura e escrita na contemporaneidade. A seguir, apresenta-se a sequência didática utilizando o meme da internet, nas aulas de Língua Portuguesa, em turmas do ensino médio.

\section{MEME DA INTERNET NAS AULAS DE LÍNGUA PORTUGUESA}

Com o propósito de não apenas desenvolver um trabalho que abordasse a natureza teórica e metalinguística do meme da internet, mas que promovesse uma discussão sobre os fatos que mobilizaram a sociedade brasileira a partir do ano de 2014, o fato histórico foi utilizado como mecanismo para se chegar a uma consciência sobre os acontecimentos sociais e políticos vividos pelos brasileiros (SOUZA, 2019).

Tal procedimento foi, inclusive, pautado nas recomendações dos documentos curriculares, que orientam que os gêneros discursivos devem ser relacionados ao seu 
contexto de produção e que as ações pedagógicas promovidas a partir deles proponham uma leitura significativa (BRASIL, 2017). Nessa perspectiva, Rojo (2005) afirma que apenas após acessarem os mais variados textos, os sujeitos podem ter condições de realizar uma leitura crítica deles, explorando todo o potencial enunciativo neles presente.

Desse modo, com o objetivo de trabalhar as características dos textos icônicoverbais e oportunizar ao aprendiz uma prática de linguagem que permitisse sua participação crítica, o meme da internet foi escolhido para o desenvolvimento de uma sequência didática em quatro etapas, como se pode verificar a seguir. Antes dessa descrição, no entanto, cabe esclarecer que uma abordagem voltada para o gênero discursivo valoriza a intenção enunciativa do enunciador, o sentido dos enunciados, a apreciação valorativa e tema; diferente perspectiva do gênero textual, que se volta apenas para a apreensão do conteúdo temático (ROJO, 2005).

\section{1 "Imagens" políticas do Brasil: uma sequência didática com meme da internet}

Com o propósito de investigar o que os alunos conheciam sobre meme da internet, no primeiro momento da sequência didática, houve a explanação das atividades que seriam desenvolvidas a partir desse gênero e a importância de se saber ler um texto icônico-verbal. Os alunos se mostraram bem receptivos com a proposta, mostrando grande interesse. Nesse momento, os educandos falaram como utilizavam memes no dia a dia e sobre quais locais e modos de circulação desse gênero discursivo.

$\mathrm{Na}$ ocasião, os alunos foram instigados a comentar sobre um conjunto de memes selecionados pela docente. As peças recolhidas de diversas fontes eletrônicas recorriam ao lugar-comum da política brasileira, tendo como protagonista Michel Temer, primeiro presidente da República brasileira a ser denunciado, durante o exercício do mandato, por suspeita de corrupção passiva.

Embora tenham surgido diferentes comentários, eles se convergiram, mostrando que os estudantes percebiam que o meme, entre outras características, visava ridicularizar comportamentos ou criticar os escândalos relacionados à corrupção de estatistas brasileiros.

Ainda, nesse momento, os alunos foram orientados a buscar informações sobre o cenário sócio-econômico-político brasileiro entre os anos de 2014 e 2019, refletindo 
"Imagens" políticas do Brasil: uma sequência didática com meme da internet nas aulas de Língua Portuguesa

sobre o papel da mídia na divulgação dos eventos. A respeito do período abordado, eles deveriam considerar a crise político-ecônomica no Brasil; a cassação do mandato e impeachment da presidente Dilma Rousseff; as investigações sobre o esquema de corrupção envolvendo Joesley Batista, proprietário da empresa de alimentos JBS, e suas acusações a Eduardo Cunha, ex-deputado e presidente da Câmara, e a Michel Temer, presidente em exercício na época; a prisão do ex-presidente Luiz Inácio Lula da Silva, decretada por Sérgio Moro, juiz federal do Tribunal Regional Federal da $4^{\mathrm{a}}$ Região; a candidatura e eleição à presidência do deputado Jair Bolsonaro, entre outros.

Os jovens foram instruídos a respeito de fontes confiáveis de pesquisa, recebendo inclusive indicações de sites, uma vez que notícias sensacionalistas e fake news se alastram no ambiente virtual. Na sequência, cada turma foi dividida em grupos de alunos, que puderam escolher um evento e o conjunto de memes produzido a partir do contexto determinado.

No segundo momento da sequência didática foram ministradas duas aulas com a intenção de contribuir com a construção interpretativa dos aprendizes a partir das imagens. Desse modo, na primeira aula, seguindo as concepções da Gramática do Design Visual, de Kress e van Leuween (1996), os alunos foram convidados a observar as três dimensões interativas da imagem a partir das personagens das peças. Assim, eles foram instigados a considerar o olhar (de demanda e de oferta), o enquadramento (distanciamento dos participantes da imagem em relação ao leitor) e a perspectiva (ângulo horizontal e vertical), conforme se verifica na figura 1 .

Figura 1 - Meme exposto para exemplificar os significados interativos a partir das concepções da Gramática do Design Visual.

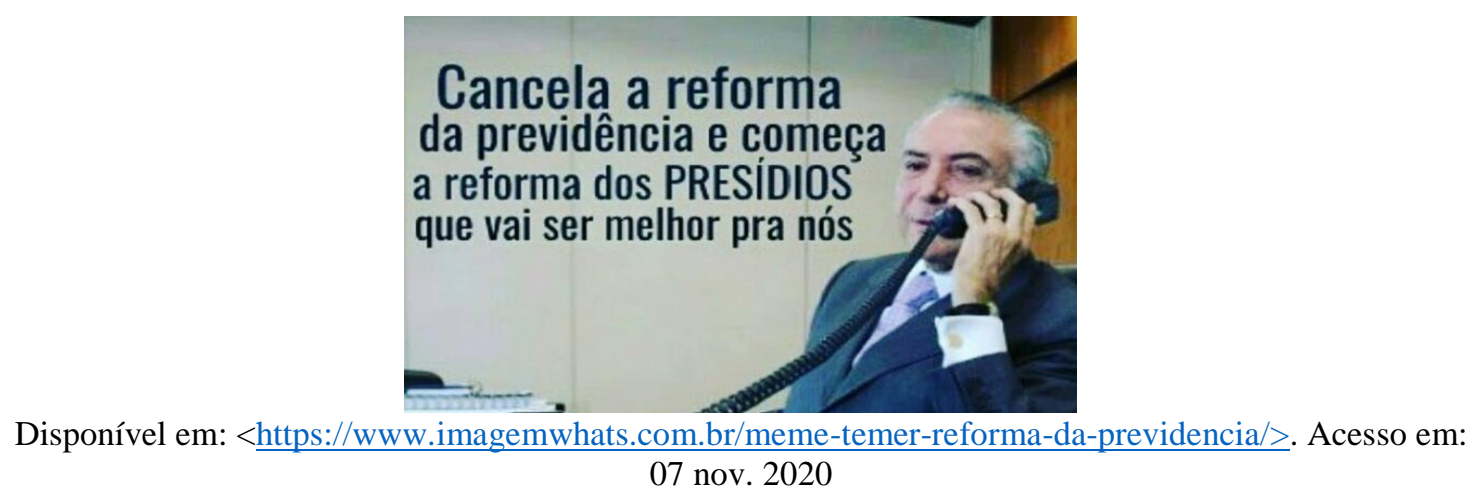


Na peça exposta, o então presidente em exercício, Michel Temer, aparece como único participante cena. Seu gesto com o braço esquerdo funciona como um vetor, ou seja, direção de seu movimento. Quanto ao contato, seu olhar é de oferta, isto é, não há contato visual direto com o observador, o que ocasiona um distanciamento. Quanto ao tamanho da moldura e tipo de enquadramento é utilizado o plano médio.

$\mathrm{Na}$ segunda aula, outro conjunto de peças com temáticas diversas foi apresentado pela docente aos alunos para que fossem abordadas questões relativas à origem do conceito de meme e sua evolução, variações linguísticas, intertextualidade, humor e figuras de linguagens, como a ironia. Também se salientou aos aprendizes que o meme tratava de um texto icônico-verbal, sendo abordados os elementos visuais e verbais que constituíam cada peça e exploradas as intencionalidades do discurso de cada meme.

No terceiro momento da sequência didática, os estudantes puderam se reunir em grupos para eleger os memes que seriam analisados e para decidir as estratégias de apresentação. Os jovens foram convidados a visitar o Museu de Memes, projeto criado por Viktor Chagas, professor da Universidade Federal Fluminense, conforme figura 2. O webmuseu traz a origem, difusão, repercussão, gênero e formatos de diversos memes nacionais, sendo referência para pesquisadores e interessados no universo dos memes. Simultaneamente a essa organização, os alunos foram orientados a confeccionar uma apresentação de slides que contivesse as informações sobre as peças que seriam expostas.

Figura 2 - Página inicial do Museu de Memes, projeto criado pelo professor Viktor Chagas, da Universidade Federal Fluminense.

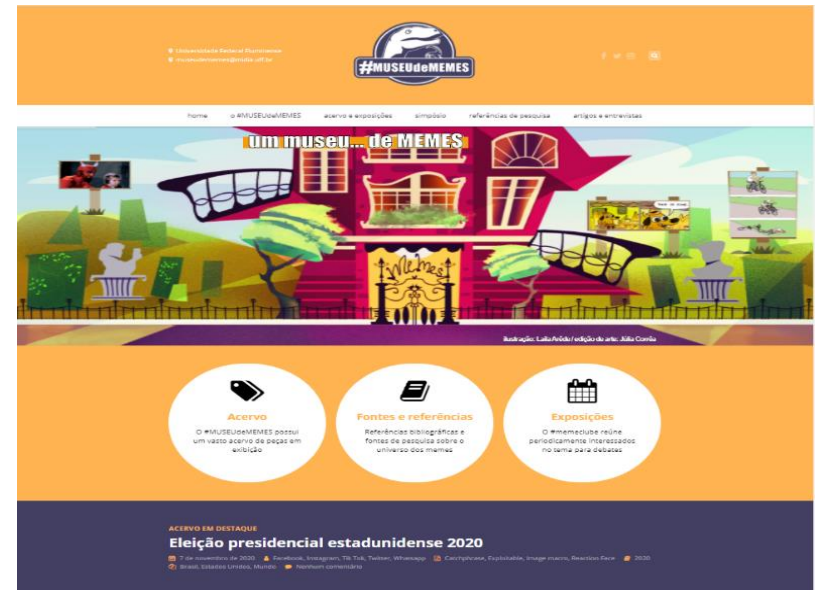

Disponível em: <https://www.museudememes.com.br/>. Acesso em: 08 nov. 2020 
"Imagens" políticas do Brasil: uma sequência didática com meme da internet nas aulas de Língua Portuguesa

A quarta parte da sequência didática foi dedicada à apresentação dos grupos. Os estudantes foram orientados a eleger de três a cinco memes que mais representassem os acontecimentos sociais e políticos no Brasil entre 2014 e 2019. Durante a comunicação oral, era necessário: a) explicar as motivações da escolha; b) observar como o meme se mostrava favorável ao aparecimento de novas peças; c) comentar sobre o contexto da produção, analisando os elementos característicos do gênero, o posicionamento político de seus produtores e a construção multimodal da peça, isto é, uma imagem vinculada a uma legenda, disposta digitalmente de maneira multimidiática (SOUZA JÚNIOR, 2014).

Para esse fim, foram destinadas quatro aulas de 50 minutos, em que os alunos na sala de multimeios não apenas explanaram sobre as peças escolhidas, como também participaram das discussões que cada meme provocava. Durante a apresentação dos trabalhos, intervenções pontuais foram efetuadas, mostrando o sentido de cada tarefa realizada na sequência (FERREIRA; VIEIRA, 2013).

Ao longo da sequência didática, os alunos realizaram vários questionamentos sobre as intenções dos memes expostos. Sob esse ponto de vista, o fato histórico funcionou como um expediente para se discutir o presente, promovendo uma participação crítica dos estudantes durante as apresentações (SOUZA, 2019).

Os alunos entenderam que, embora as imagens possam ser parafraseadas pela linguagem verbal, elas apenas são totalmente compreendidas pela visão (FARACO, MOURA; MARUXO, 2016). Da mesma forma, perceberam que, se por um lado, havia situações em que as imagens podiam ser dispensadas sem prejuízo do entendimento; em outras, elas eram essenciais para o entendimento de um evento linguístico.

No decorrer das apresentações, foi ressaltado com os alunos que, nas representações visuais do meme da internet, é necessário considerar tanto os processos narrativos como os conceituais. Desse modo, gradualmente, os aprendizes entenderam que, na categoria narrativa, existem os participantes (seres humanos ou não), que fazem algo para alguém ou recebendo algo de outrem e as circunstâncias, que se referem a instrumentos utilizados pelos participantes, local, companhia; já na categoria conceitual, os participantes são subordinados ou não a outros elementos visuais (SOUZA JÚNIOR, 2014). 


\subsection{Avaliando os resultados da sequência didática}

$\mathrm{Na}$ exposição dos trabalhos, os alunos tiveram como suporte a internet. Muitas peças apresentadas traziam personalidades já conhecidas, mostrando situações que motivaram as discussões. Sob esse ponto de vista, o meme da internet se configurou como "meio" e "palco" de produção de conhecimentos educacionais, que permitiram aos aprendizes comparar experiências significativas de sua existência (CUNHA; PRADO, 2017).

Valendo-se do princípio do design, os alunos verificaram como a reelaboração de determinado meme ocorria. Nas peças expostas, notou-se esse remix no momento em que um meme foi ressignificado para originar outras peças. Além disso, a análise dos memes se pautou nas condições de produção e na percepção de lugar, uma vez que o discurso enquanto instrumento de prática política altera as relações sociais originando demandas próprias. Conforme Lima (2003, p. 82), os fatos "reclamam sentidos, cuja materialidade não é possível de ser apreendida em si, mas no discurso", ou seja, a história não é uma sucessão de fatos cronológicos com sentido já dado.

Nenhum meme exposto apresentou discurso de ódio ou linguagem inconveniente, comprovando que os alunos souberam separar os limites entre liberdade de expressão e agressão a direitos constituídos. Para a apresentação, a maioria dos grupos teve como critério buscar pelos memes mais conhecidos na internet ou compartilhados nas redes sociais. No entanto, houve grupos que se basearam no próprio gosto: "Escolhemos memes que achamos engraçados e que tivessem um tipo de humor que nós gostamos", declarou uma aluna. "Alguns memes foram escolhidos porque estavam de acordo com o gosto e conhecimento de cada um sobre política", informou outra estudante.

Assim, os memes apresentados, sempre bem espirituosos, fizeram uma retrospectiva dos acontecimentos sociopolíticos vivenciados pelos jovens ou das reverberações desses eventos, conforme demonstra a figura 3. 
"Imagens" políticas do Brasil: uma sequência didática com meme da internet nas aulas de Língua Portuguesa

Figura 3 - Peça exposta por um dos grupos mostra, de maneira bem-humorada, o posicionamento dos aprendizes a respeito dos casos de corrupção passiva envolvendo políticos brasileiros.

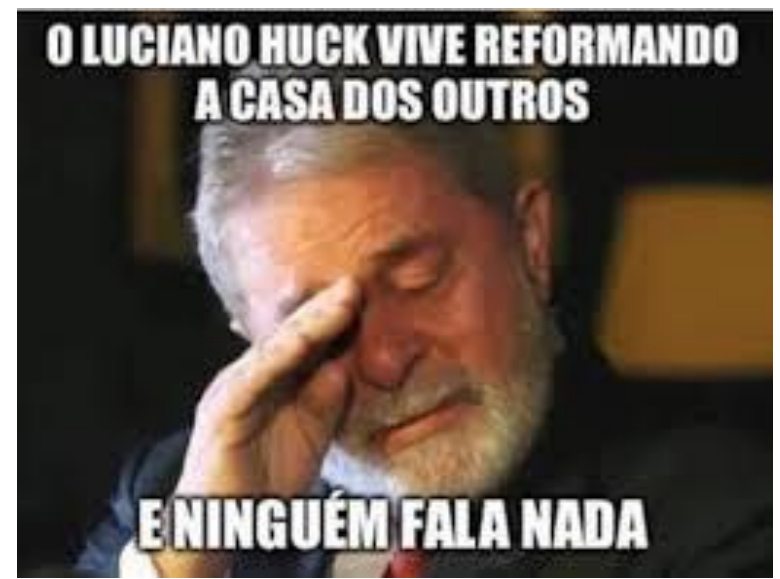

Disponível em: <https://me.me/i/o-luciano-huck-vive-reformando-a-casa-dos-outros-eninguem5221f1149d294986ac1463ebadf8d661>. Acesso em: 5 nov. 2020

No meme apresentado, a expressão facial do ex-presidente sugere desolação e tristeza. Na legenda que representa sua fala, ocorre uma intertextualidade. Nela há a menção ao apresentador de televisão Luciano Huck, que protagoniza um quadro em seu programa, no qual os participantes ganham uma reforma na própria casa. $\mathrm{O}$ humor da peça decorre da associação desse quadro televisivo à condenação do ex-presidente por corrupção passiva e lavagem de dinheiro em uma ação penal envolvendo um triplex no Guarujá (SP) ${ }^{1}$.

Um grupo, quando questionado sobre os critérios de escolha das peças expostas, justificou o seguinte: “O meme pode vir em forma de reclamação, geralmente usado para poder criticar algo de errado que está acontecendo no governo; por isso temos muitos memes com a intertextualidade e duplo sentido", disse uma aluna da turma.

Assim sendo, o meme da internet foi elemento importante para a formação do pensamento crítico, permitindo entender um determinado sentido histórico. Em vista disso, a interpretação de cada peça exigiu conhecer as personagens inseridas no tempo e no espaço. Entretanto, Escalante (2016, p. 93) ressalta que isso não quer dizer que todos os educandos aprenderão determinado conteúdo com o meme da internet; mas, em algum momento, o gênero poderá estimular a curiosidade daqueles que não conseguirem entender o seu código; já que a leitura de uma peça envolve "saber ler; saber em qual língua o meme está escrito; conhecer as referências culturais que estarão presentes nele; saber manusear o aparato técnico em que ele está exposto, etc.”. 
Durante a realização da sequência didática, os alunos se mostraram entusiasmados em todas as etapas, principalmente durante as apresentações dos grupos, que eram acompanhadas de discussões muito frutíferas. Segundo eles, "o trabalho foi diferenciado pelo simples fato de ser sobre algo novo, uma coisa que faz muito sucesso nas redes sociais". E quando questionados sobre a metodologia de trabalho desenvolvida, os jovens declararam que as aulas expositivas foram bem dinâmicas, as apresentações foram esclarecedoras e os debates produtivos. Os estudantes aprovaram o método, dizendo que o trabalho havia sido prático, pois "a maioria das informações eram de fácil acesso e podiam ser baixadas rapidamente”. Ademais, realizar as atividades em grupo permitiu que socializassem opiniões para se chegar a um acordo: "Fazer o trabalho em grupo foi algo bom, porque um ajudou o outro nas ideias e opiniões etc.", declarou uma aluna. "[O trabalho] foi bom, cada um falou de uma coisa diferente, nada igual", afirmou outro aluno.

Com efeito, trabalhar com meme da internet nas aulas de Língua Portuguesa gerou um debate que mostrou aos aprendizes que, diferente do ataque a direitos, a divergência de ideias permite a ampliação de posicionamentos e argumentos (BRASIL, 2017). Nesse sentido, Dolz e Schneuwly (1999, p. 10) reforçam que:

Toda introdução de um gênero na escola é o resultado de uma decisão
didática que visa a objetivos precisos de aprendizagem que são sempre de
dois tipos: trata-se de aprender a dominar o gênero, primeiramente, para
melhor conhecê-lo, melhor produzi-lo na escola e fora dela, e, em segundo
lugar, para desenvolver capacidades que ultrapassam o gênero e que são
transferíveis para outros gêneros.

No decorrer das aulas expositivas, as características dos textos icônico-verbais foram tratadas, levando o aprendiz a perceber que esse tipo de texto possui em sua constituição vários recursos semióticos como sons, escrita, imagens, cores e ícones. De fato, esse tipo de texto abarca não apenas os aspectos visuais das fotografias, desenhos, pinturas, caricaturas, como a disposição gráfica do texto no papel ou na tela (FERREIRA; VIEIRA, 2013). Nas palavras de um aluno: "Devemos ver a legenda e imagem, porque alguns memes só vão fazer sentido se soubermos ligar o significado da imagem ao que ela quer mostrar ou o que significa e a legenda pode dar um ar de ironia ou algo mais profundo".

Por certo, ao produzir um meme da internet, seu criador escolhe ressaltar aspectos positivos ou negativos da situação ou personagem. Desse modo, nos memes, é 
"Imagens" políticas do Brasil: uma sequência didática com meme da internet nas aulas de Língua Portuguesa

comum que as atitudes (representação dos gestos e/ou expressões faciais) sejam veiculadas por meio de imagens e não de palavras. Pelo meme, seu criador expressa atitudes com as quais constrói o sentido da peça, sendo possível expressar e representar a realidade que o cerca. Tal concepção foi confirmada pela declaração de um aluno, participante da sequência didática, ao dizer que "o procedimento para ler um meme é simplesmente estar por dentro dos assuntos do momento, do que está repercutindo, e interpretar com humor".

Nesse sentido, o contexto exterior a uma produção comporta além de um ambiente compartilhado pelos interlocutores, juízos de valor, conhecimentos e compreensão da situação comum. Conforme diz Bakhtin (2003), toda interpretação é a união de uma determinada produção com outras, sendo que toda palavra de um texto permite ir além de seus limites.

Os estudantes perceberam ainda que ao preferir um determinado gesto a outro para expressar uma atitude, o criador do meme relaciona, de maneira consciente, o movimento do corpo, braços, mãos ou cabeça da personagem ao que é dito ou expresso na legenda. De acordo com um aluno, “o principal é a imagem, depois vem a legenda para ficar engraçado, [pois] sempre representa uma coisa do seu dia a dia”. No entanto, muitas vezes, as peças não dependem de um texto-fonte, exibindo imagens que possuem autonomia suficiente para seu entendimento (BELMIRO, 2012). A isso um aluno acrescentou: "Muitos memes, às vezes, não têm legenda, somente uma imagem, essas imagens dão contexto ao meme".

Simultaneamente à exposição dos memes da internet, não se deixou de mencionar os textos icônico-verbais já consagrados pela escola, como a charge, o cartum, a tirinha, o cartaz, o anúncio publicitário, os poemas visuais, o relatório de experiência, entre outros. Também foram mencionados os gêneros essencialmente digitais, por exemplo, emoticons, emojis, gif e homepage. Essa abordagem demonstrou que nenhum gênero é menor que outro, pois compreender um relatório de experiência é tão importante como atribuir sentidos a um meme da internet (BRASIL, 2017).

Ao se considerar os jovens enquanto sujeitos ativos na construção de seus saberes, a sequência didática valorizou o conhecimento anterior dos alunos, adotando atividades diversas, como a pesquisa, a comunicação oral e o debate. Ademais, a proposta centrou-se na problematização do tema, promovendo uma interação que levou 
à sistematização dos saberes (DOLZ; NOVERRAZ; SCHNEUWLY, 2004). Com efeito, tal procedimento demonstrou que os eventos da cultura digital podem contribuir para uma participação mais crítica dos jovens nas práticas de linguagem (BRASIL, 2017).

\section{CONSIDERAÇÕES FINAIS}

Com o objetivo de compartilhar práticas de linguagem que oportunizassem a participação crítica do aprendiz em atividades de leitura, este relato de experiência profissional apresentou uma sequência didática desenvolvida com alunos do ensino médio de uma escola pública do município de Belo Horizonte, em que se considerou o meme da internet como unidade de trabalho.

Assim, valendo-se de memes publicados na internet, entre os anos 2014 e 2019, os estudantes elaboraram diferentes representações do Brasil. Diante das peças, os alunos observaram como a imagem que se tem da realidade brasileira sofre mudanças ao longo do tempo. Essas alterações também dependeram do olhar deles, da finalidade de cada meme escolhido, do público leitor e da época. Assim, os alunos apreenderam como o Brasil pode ser visto a partir das lentes de um conjunto de memes.

Organizados de diferentes maneiras, os estudantes puderam realizar pesquisas individualmente, elegeram as peças a serem analisadas em grupos menores, apresentaram o resultado das análises e discutiram as potencialidades do meme com toda a classe. Ao se diversificar as atividades em torno do meme da internet, além de abordar os acontecimentos políticos que as peças aludiam, foram realizadas com os alunos atividades de leitura e análise do gênero. Ao final da sequência didática, oportunizou-se que os jovens refletissem sobre as ações realizadas, expondo os conhecimentos construídos sobre o objeto estudado e suas opiniões sobre as estratégias pedagógicas.

Essa proposta didática ilustrou como o componente Língua Portuguesa pode promover práticas de leitura de maneira crítica. No conjunto de ações desenvolvidas, foram avaliados tanto a intenção comunicativa de quem produziu o meme da internet como o contexto sociopolítico das peças. Ao longo da sequência, as características do texto icônico-verbal foram tratadas, levando o aprendiz a perceber que esse tipo de texto 
"Imagens" políticas do Brasil: uma sequência didática com meme da internet nas aulas de Língua Portuguesa

possui em sua constituição diferentes recursos semióticos. Percebeu-se, ainda, como o meme permitia ao aprendiz expressar seu pensamento, mostrando seu posicionamento.

Durante as atividades desenvolvidas, os alunos entenderam que a mudança do contexto político levou a uma mudança na representação da realidade brasileira. Ainda perceberam que o meme circula no ambiente virtual não apenas compartilhando conteúdos, mas exigindo que os leitores articulem os conhecimentos advindos de várias fontes.

A sequência didática confirmou que, na aprendizagem dos gêneros, existe a real necessidade de se planejar atividades que levem os alunos a construir conceitos a partir do aprender "a fazer". A experiência mostrou ainda que, em Língua Portuguesa, o meme da internet pode contribuir para o posicionamento crítico dos aprendizes nas diferentes práticas de linguagem.

Se, por um lado, a escola possui e produz práticas diversas de construção de subjetividade dos sujeitos; por outro lado, ela abarca e é perpassada pelos discursos presentes nos vários gêneros discursivos da contemporaneidade. Tais questões colocam os educadores diante do desafio de incluir temas da internet nas disciplinas escolares, garantindo que os aprendizes tenham condições de ler criticamente todo conteúdo veiculado pela rede.

\section{Referências}

ANTUNES, Irlandé Costa. Língua, gêneros textuais e ensino: considerações teóricas e implicações pedagógicas. Perspectiva, Florianópolis, v. 20, n. 1, p. 65-76, jan./jun. 2002.

BAKHTIN, Mikhail. Os gêneros do discurso. In: . Estética da criação verbal.

Trad. P. Bezerra. São Paulo: Martins Fontes, 2003. p. 261-306.

BARRETO, Krícia Helena. Os memes e as interações sociais na internet: Uma interface entre práticas rituais e estudos de face. Tese (Doutorado) - Universidade Federal de Juiz de Fora, Faculdade de Letras. Programa de Pós-Graduação em Linguística, 2015. Disponível em: <http://www.ufjf.br/ppglinguistica/files/2009/12/BARRETO-Kr\%C3\%ADcia-HelenaTESE-2015.pdf >. Acesso em: 2 nov. 2017.

BELMIRO, Celia Abicalil. A imagem e suas formas de visualidade nos livros didáticos de Português. In: Educação \& Sociedade, ano XXI, n. 72, Agosto/2000. Disponível em: <http://www.scielo.br/pdf/es/v21n72/4191.pdf >. Acesso em: 30 abr. 2019. 
. Entre modos de ver e modos de ler, o dizer. In: Educação em Revista, Belo Horizonte, v. 28, n. 04, p. 105-131, dez. 2012. Disponível em: <http://www.scielo.br/pdf/edur/v28n4/05.pdf>. Acesso em: 30 abr. 2019.

BRASIL. Base Nacional Comum Curricular (BNCC). Educação é a Base. Brasília, MEC/CONSED/UNDIME, 2017. Disponível em: $<$ http://basenacionalcomum.mec.gov.br/wp-content/uploads/2018/02/bncc-20dezsite.pdf>. Acesso em: 10 set. 2018.

CHAGAS, Viktor. A febre dos memes de política. In: Mídias, Política e Eleições da $40^{\circ}$ Encontro Anual da Associação Nacional de Pós-Graduação e Pesquisa em Ciências Sociais (ANPOCS), Caxambu, Minas Gerais, 2016. Disponível em: $<$ https://www.anpocs.com/index.php/papers-40-encontro/st-10/st17-8/10320-a-febredos-memes-de-politica/file>. Acesso em: 2 nov. 2017.

COSCARELLI, Carla Viana. Os dons do hipertexto. In: Littera: Revista de Linguística e Literatura. Pedro Leopoldo: Faculdades Integradas Pedro Leopoldo, v.4, n.4, jul./dez., 2006. p. 7-19. Disponível em:

<http://www.letras.ufmg.br/carlacoscarelli/publicacoes/DonsDoHipertexto.pdf>. Acesso em: 25 mai. 2017.

CUNHA, Nara Rúbia de Carvalho; PRADO, Guilherme do Val Toledo. Memórias e sensibilidades numa produção de conhecimentos histórico-educacionais. In: Revista Memória em Rede, Pelotas, v. 10, n. 17, Jul./Dez. 2017. Disponível em: <https://periodicos.ufpel.edu.br/ojs2/index.php/Memoria/article/view/11023>. Acesso em: 20 ago. 2020.

DOLZ, Joaquim; SCHNEUWLY, Bernard. Os gêneros escolares: das práticas de linguagem aos objetos de ensino. Revista Brasileira de Educação, São Paulo, n. 11, p. 5-16, maio-ago. 1999. Disponível em:

<https://www.researchgate.net/publication/237513754_Os_generos_escolares_Das_prat icas_de_linguagem_aos_objetos_de_ensino>. Acesso em: 20 ago. 2020.

DOLZ, J.; NOVERRAZ, M.; SCHNEUWLY, B. Sequências didáticas para o oral e a escrita: apresentação de um procedimento. In: SCHNEUWLY, B.; DOLZ, J. (Orgs.). Gêneros orais e escritos na escola. Campinas: Mercado das Letras, 2004. Disponível em:

https://edisciplinas.usp.br/pluginfile.php/5766714/mod_resource/content/1/DOLZ\%3B \%20NOVERRAZ\%3B\%20SCHNEUWLY.\%20Sequ\%C3\%AAncias\%20Did\%C3\%A1 ticas\%20para\%20o\%20oral\%20e\%20para\%20a\%20escrita\%20apresenta\%C3\%A7\%C3 \%A3o\%20de\%20um\%20procedimento.pdf. Acesso em: 8 nov. 2020.

ESCALANTE, Pollyana Rodrigues Pessoa. O potencial comunicativo dos memes: formas de letramento na rede digital. Dissertação (Mestrado) - Universidade do Estado do Rio de Janeiro. Faculdade de Comunicação Social, 2016. Disponível em: <http://www.ppgcom.uerj.br/wp-content/uploads/Disserta\%C3\%A7\%C3\%A3oPollyana-Escalante.pdf>. Acesso em: 2 nov. 2017. 
"Imagens" políticas do Brasil: uma sequência didática com meme da internet nas aulas de Língua Portuguesa

EUZÉBIO, Michelle Donizeth; CERUTTI-RIZZATTI, Mary Elizabeth. Usos Sociais da Escrita: Um Estudo sobre Práticas e Eventos de Letramento na Vivência de Professoras Alfabetizadoras. In: Linguagem em (Dis)curso, Tubarão, SC, v. 13, n. 1, p. 13-34, jan./abr. 2013. p. 13-34. Disponível em:

http://www.scielo.br/pdf/ld/v13n1/a02v13n1.pdf. Acesso em: 2 nov. 2017.

FARACO, Carlos Emílio; MOURA, Francisco Marto de; MARUXO JR., José Hamilton. Língua portuguesa: linguagem e interação. Vol. 1, 3. ed. São Paulo: Ática, 2016.

FERREIRA, Helena Maria; VIEIRA, Mauricéia Silva de Paula. Gêneros textuais e discursivos: guia de estudos. Lavras: UFLA, 2013. Disponível em:

https://docplayer.com.br/5963825-Generos-textuais-e-discursivos.html. Acesso em: 20 ago. 2020.

KOBASHIGAWA, A. H.; ATHAYDE, B. A. C.; MATOS, K. F. de OLIVEIRA; CAMELO, M. H.; FALCONI, S. Estação ciência: formação de educadores para o ensino de ciências nas séries iniciais do ensino fundamental. In: IV Seminário Nacional ABC na Educação Científica. São Paulo, 2008. p. 212-217. Disponível em:

http://www.cienciamao.usp.br/dados/smm/_estacaocienciaformacaodeeducadoresparaoe nsinodecienciasnasseriesiniciaisdoensinofundamental.trabalho.pdf. Acesso em: 31 jun. 2020.

KRESS, Gunther; VAN LEEUWEN, Theo. Reading images: the grammar of visual design. London and New York: Routledge, 1996.

LIMA, Maria Emília Amarante Torres. Análise do discurso e/ou análise de conteúdo. In: Psicologia em Revista, Belo Horizonte, v. 9, n. 13, p. 76-88, jun. 2003. Disponível em: http://periodicos.pucminas.br/index.php/psicologiaemrevista/article/view/166/179 Acesso em: 13 dez. 2017.

MARCUSCHI, Luiz Antonio. Gêneros textuais: definição e funcionalidade. In: Gêneros Textuais e ensino. Organizado por Ângela Paiva Dionísio, Anna Rachel Machado e Maria Auxiliadora Bezerra. 3 ed. - Rio de Janeiro: Lucerna, 2005. páginas 19-36. Disponível em:

https://edisciplinas.usp.br/pluginfile.php/133018/mod_resource/content/3/Art_Marcusch i_G\%C3\%AAneros textuais_defini\%C3\%A7\%C3\%B5es_funcionalidade.pdf. Acesso em: 20 ago. 2020.

PEREIRA, Luana Gomes. Leitura, gêneros textuais e novas tecnologias. In: \# Tear: Revista de Educação Ciência e Tecnologia, Canoas, v.1, n.1, 2012. Disponível em: https://periodicos.ifrs.edu.br/index.php/tear/article/view/1709. Acesso em: 3 mai. 2019.

RECUERO, Raquel da Cunha. Memes em weblogs: proposta de uma taxonomia. Revista FAMECOS, Porto Alegre, n. 32, p. 23-31, abril de 2007. Disponível em: http://revistaseletronicas.pucrs.br/ojs/index.php/revistafamecos/article/view/3411. Acesso em: 2 nov. 2017. 
RIBEIRO, Ana Elisa. Multimodalidade e Produção de Textos: Questões para o Letramento na Atualidade. In: Signo, Santa Cruz do Sul, v. 38, n. 64, p. 21-34, jan./jun. 2013. [ISSN 1982-2014]. Disponível em: http://online.unisc.br/seer/index.php/signo. Acesso em: 4 nov. 2017.

ROJO, Roxane. Gêneros do discurso e gêneros textuais: questões teóricas e aplicadas In: J. L. Meurer, A. Bonini, \& D. Motta-Roth (Org.), Gêneros: teorias, métodos, debates. São Paulo: Parábola, 2005.

SHIFMAN, Limor. Memes in digital culture. MIT press, 2014.

SOARES, Magda. Novas práticas de leitura e escrita: letramento na cibercultura. In: Educ. Soc., Campinas, vol. 23, n. 81, p. 143-160, dez. 2002 Disponível em: http://www.scielo.br/pdf/es/v23n81/13935.pdf. Acesso em: 11 mai. 2017.

SOUZA JÚNIOR, J. de. Memes pluralistas - práticas linguístico-midiáticas em fenômenos bilíngues: um estudo sistêmico-funcional e multimodal sobre propagação via corpora digitais. 2014. 173 f. Dissertação (Mestrado em Linguística) - Instituto de Letras, Universidade do Estado do Rio de Janeiro, Rio de Janeiro, 2014. Disponível em: http://www.bdtd.uerj.br/tde_busca/arquivo.php?codArquivo=8781. Acesso em: 20 ago. 2020.

SOUZA, Maria Alice de. Memes de internet e educação: Uma sequência didática para as aulas de História E Língua Portuguesa. In: Periferia, v. 11, n. 1, p. 193-213, jan./abr. 2019.

Recebido em: 31/08/2020

Aceito em: 16/11/2020

\footnotetext{
1 ENTENDA a condenação de Lula no caso do triplex. Disponível em: <https://g1.globo.com/politica/noticia/entenda-a-condenacao-de-lula-no-caso-do-triplex.ghtml>. Acesso em: 8 nov. 2020.
} 